\title{
Chemotaxis and chemiluminescence responses of synovial fluid polymorphonuclear leucocytes during acute reactive arthritis
}

\author{
Marjatta Leirisalo-Repo, Anneli Lauhio, Heikki Repo
}

\begin{abstract}
The chemotaxis and chemiluminescence responses of polymorphonuclear leucocytes (PMN) of synovial fluid and peripheral blood from patients with acute reactive arthritis were studied. Rates of chemotactic and chemokinetic migration of synovial fluid PMN were significantly decreased. In addition, chemiluminescence responses tended to be depressed, suggesting that the cells were deactivated for both chemotaxis and production of oxygen derived free radicals. Such deactivation has been described previously as a characteristic of synovial fluid PMN in rheumatoid arthritis. Compared with those with a mild disease, patients with severe acute reactive arthritis had higher chemiluminescence responses of synovial fluid PMN to phorbol myristate acetate during acute disease and developed increased migration of peripheral blood PMN towards zymosan treated serum after recovery from the disease. This supports the view that hyperreactive PMN contribute to the development of severe inflammatory symptoms in acute reactive arthritis.
\end{abstract}

Reactive arthritis, a sterile joint inflammation preceded by an infection elsewhere in the body, may be triggered by an enteric or urogenital infection. The microbes triggering reactive arthritis include yersinia, salmonella, shigella, campylobacter, chlamydia, and possibly gonococcus. ${ }^{12}$ The acute reactive arthritis is characterised by inflammatory signs that are both local (synovitis with polymorphonuclear cells predominating in the synovial fluid) and systemic (fever, conjunctivitis, iritis, urethritis, and mucocutaneous symptoms).

Peripheral blood polymorphonuclear leucocytes (PMN) of HLA-B27 positive patients with yersinia arthritis show increased chemotaxis, ${ }^{3}$ and PMN of patients who had recovered from a severe acute disease $e^{4}$ or those who have inflammatory sequelae ${ }^{5}$ tend to show enhanced chemiluminescence, suggesting that the cells are primed-that is, rendered hyperreactivefor instance, by mediators of inflammation. ${ }^{6} 7$ Chemotaxis of the peripheral blood PMN of patients with rheumatoid arthritis is depressed 89 or normal, ${ }^{1011}$ and superoxide production is enhanced. ${ }^{12}$ Synovial fluid PMN, however, show depressed chemotaxis ${ }^{13}$ and depressed chemiluminescence responses. ${ }^{14}$ This indicates that the synovial fluid cells in rheumatoid arthritis tend to be deactivated for both chemotaxis and production of oxygen derived free radicals. ${ }^{6}$ In reactive arthritis the functional capacities of synovial fluid PMN are not known. Therefore, we set out to study chemotaxis and chemiluminescence responses of synovial fluid and peripheral blood PMN of patients with acute reactive arthritis, and to compare the responses with those of peripheral blood PMN of healthy controls.

\section{Patients and methods}

PATIENTS

We studied 12 patients with acute reactive arthritis, who presented with acute oligoarthritis or polyarthritis mainly affecting the lower extremities. The patients were treated at the Helsinki University Central Hospital or at the Aurora Hospital, Helsinki. Table 1 shows the characteristics of the patients. At the time when the synovial fluid and blood samples were taken the patients were treated with non-steroidal antiinflammatory agents. Healthy HLA-B27 negative members of the hospital and laboratory staff served as controls. A patient and a control formed a fixed pair which was tested at the acute phase of the disease, one month later, and at six months after recovery. Two patients were tested at the acute phase only; one was not reached for subsequent testing and the other with acute colitis later developed Crohn's disease. To study the relation between severity of inflammation and phagocyte function the patients were divided into two groups: those with severe acute disease $(n=5)$ and those with mild acute disease $(n=7$, table 1$)$.

\section{CELLS}

All the patients had effusion of the knee joint, which was aspirated. The leucocyte counts in the synovial fluid varied from $4 \times 10^{9}$ to $12 \cdot 4 \times 10^{9} / 1$ (mean $\left.7 \cdot 7 \times 10^{9} / 1\right)$. The proportion of PMN varied from 62 to $96 \%$ (mean $78 \cdot 8 \%$ ). The synovial fluid was immediately diluted (1:5) with RPMI 1640 (Orion Co, Helsinki) containing $1 \mathrm{mM}$ HEPES ( $N$-2-hydroxyethylpiperazine- $N^{\prime}-2$ ethane sulphonic acid) and centrifuged. The cells were then washed once with Hanks's balanced salt solution (HBSS). Buffy coat cells of peripheral blood of the patient and the control were separated from heparinised venous blood by dextran sedimentation. Polymorphonuclear leucocytes were separated from both buffy coat cells and synovial fluid cells by Ficoll-Isopaque density gradient centrifugation ${ }^{15}$ followed by hypotonic lysis of the red cells. The PMN were 95-99\% pure. Synovial fluid PMN stained by the May-Grünwald-Giemsa technique were morphologically normal and the viability was $>90 \%$ as judged by eosin exclusion test. 
Table 1: Clinical characteristics of the patients

\begin{tabular}{|c|c|c|c|c|c|c|c|c|}
\hline Sex & $\begin{array}{l}\text { Age } \\
\text { (years) }\end{array}$ & $B 27$ & $\begin{array}{l}\text { Joint } \\
\text { count }\end{array}$ & $\begin{array}{l}\text { Highest } \\
E S R(\mathrm{~mm} / \mathrm{h})\end{array}$ & $\begin{array}{l}\text { Extra-articular } \\
\text { symptoms }\end{array}$ & $\begin{array}{l}\text { Severe } \\
\text { disease }\end{array}$ & $\begin{array}{l}\text { Duration } \\
\text { of synovitis } \\
\text { (weeks) }\end{array}$ & $\begin{array}{l}\text { Triggering } \\
\text { factor }\end{array}$ \\
\hline $\mathbf{M}$ & 27 & + & 3 & 98 & - & - & 11 & Campylobacter \\
\hline $\mathrm{F}$ & 23 & - & 6 & 92 & - & - & 2 & Acute colitis \\
\hline$M$ & 40 & + & 1 & 99 & Urethritis & + & 3 & ? \\
\hline $\mathbf{M}$ & 44 & - & 5 & 86 & Urethritis & - & 2 & Gonococcus \\
\hline M & 28 & + & 7 & 125 & Urethritis & + & 4 & Diarrhoea \\
\hline M & 26 & + & 7 & 103 & - & - & 4 & Yersinia \\
\hline M & 18 & + & 9 & 110 & Urethritis & + & 6 & Salmonella \\
\hline M & 27 & + & 6 & 125 & Iritis & + & 2 & Yersinia \\
\hline F & 24 & + & 6 & 102 & $\begin{array}{l}\text { Conjunctivitis, } \\
\text { urethritis }\end{array}$ & - & 3 & Yersinia \\
\hline $\mathbf{M}$ & 20 & + & 1 & 15 & - & - & 16 & Chlamydia \\
\hline M & 30 & + & 5 & 119 & Urethritis & + & 3 & Salmonella \\
\hline $\mathbf{M}$ & 20 & + & 6 & 4 & Balanitis & - & 12 & Chlamydia \\
\hline
\end{tabular}

* Severe acute disease $=$ the presence of at least two of the three following characteristics: highest erythrocyte sedimentation rate (ESR) $\geqslant 110 \mathrm{~mm} / \mathrm{h}$; highest white blood cell count $\geqslant 10 \times 10^{9} / \mathrm{l}$, and presence of extra-articular manifestations (see ref 4 ).

\section{POLYMORPHONUCLEAR LEUCOCYTE}

\section{STIMULATING AGENTS}

Zymosan treated serum (ZTS) was prepared from pooled normal human serum. ${ }^{16} \mathrm{~N}$-formylmethionyl-leucyl-phenylalanine (FMLP) and phorbol myristate acetate were purchased from Sigma Chemical Co, St Louis, Missouri. Opsonised zymosan particles were prepared as described previously. ${ }^{4}$

\section{MEMBRANE FILTER ASSAY}

The leading front modification ${ }^{17}$ of the Boyden chamber technique ${ }^{18}$ was applied according to Wilkinson $^{19}$ using $2 \times 10^{5}$ purified PMN for each $3 \mu \mathrm{m}$ pore size Millipore filter. The attractants and reference solutions were used above and below the filters as follows: HBSS/ HBSS in studies of spontaneous locomotion, $0 \cdot 2 \% \mathrm{HSA} / 0 \cdot 2 \% \mathrm{HSA}$ (human serum albumin, AB Kabi, Stockholm, Sweden) and $12 \%$ ZTS/ $12 \%$ ZTS in studies of chemokinesis, and 3\% ZTS/12\% ZTS in studies of chemotaxis. The filters were incubated for 55 minutes at $37^{\circ} \mathrm{C}$. The distance of the leading front of the cells migrating was determined in five microscopical fields of each of the triplicate filters.

AGAROSE ASSAY

An agarose assay was used as described previously. ${ }^{16}$ The agarose medium was $1 \%$ agarose (Biomedical Division of Marine Colloids, Rockland, Maine) and 1\% HSA. The rates of random migration in HSA, those of chemokinetic migration in $4 \% \mathrm{ZTS}$, and in $1 \times 10^{-8} \mathrm{M}$ FMLP, and those of chemotactic migration in response to ZTS and $5 \times 10^{-7} \mathrm{M}$ FMLP were determined by measuring the distance of migration of $2.5 \times 10^{5} \mathrm{PMN}$ in quadruplicate tests.

\section{CHEMILUMINESCENCE ASSAY}

The chemiluminescence response was measured with an LKB luminometer (model 1250, Wallac) fitted with a $37^{\circ} \mathrm{C}$ water jacketed sample holder. Polymorphonuclear leucocytes $\left(2 \times 10^{5}\right)$ in 100 $\mu l$ of phosphate buffered saline (PBS) were kept at $37^{\circ} \mathrm{C}$ for one minute and mixed with $100 \mu \mathrm{l}$ of PBS, $100 \mu \mathrm{l}$ of FMLP $\left(10^{-5} \mathrm{M}\right), 100 \mu \mathrm{l}$ of phorbol myristate acetate $(1 \mu \mathrm{g} / \mathrm{ml}$ in PBS), or $100 \mu \mathrm{l}$ of opsonised zymosan particles, and with $200 \mu \mathrm{l}$ of the luminol solution $(10 \mu \mathrm{g} / \mathrm{ml}$ in PBS;
Fluka AG, Buchs SG, Switzerland). The height of the curve as millivolts $(\mathrm{mV})$ at one minute intervals and the area under the curve $\left(\mathrm{cm}^{2}\right)$ were determined.

STATISTICAL METHODS

Comparisons were made using the paired sample

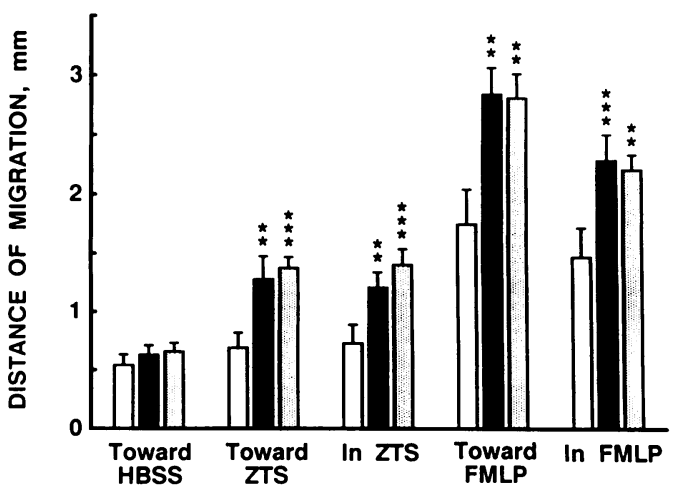

Figure 1: Migration of synovial fluid polymorphonuclear leucocytes (PMN) (open columns) and peripheral blood $P M N$ of the patients (black columns) and controls (hatched columns) under agarose at the acute phase of the disease. HBSS = Hanks's balanced salt solution; $Z T S=z y m o s a n$ treated serum; $F M L P=N$-formyl-methionyl-leucylphenylalanine. Each bar indicates ISE. The significance of the difference between synovial fluid PMN and peripheral blood $P M N$ is indicated by asterisks. ** $p<0 \cdot 01$;

${ }_{* * *}<<0.001$. The difference between the patients' peripheral and the control polymorphonuclear leucocyte migration in ZTS was statistically significant $(p<0 \cdot 05)$.

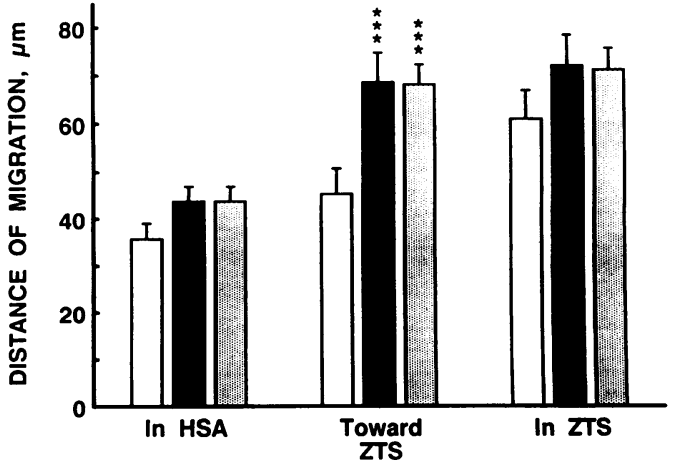

Figure 2: Migration of synovial fluid polymorphonuclear leucocytes (PMN) (open columns) and peripheral blood $P M N$ of the patients (black columns) and the controls (hatched columns) in the filter at the acute phase of the disease. $H S A=$ human serum albumin; $Z T S=z y m o s a n$ treated serum. Each bar indicates $I S E$. The significance of the difference between synovial cells and peripheral blood the difference between synovial cells and peri
cells is indicated by asterisks. ${ }^{* * *} p<0 \cdot 001$. 
Table 2: Functions of peripheral blood polymorphonuclear leucocytes at one month and at six months (after recovery) of patients with acute reactive arthritis. The figures are expressed as means (SD)

\begin{tabular}{|c|c|c|c|c|}
\hline & \multicolumn{2}{|c|}{ At one month $(n=11)$} & \multicolumn{2}{|c|}{ After recovery $(n=10)$} \\
\hline & Patients & Controls & Patients & Controls \\
\hline $\begin{array}{l}\text { Migration under agarose }(\mathrm{mm}) \text { : } \\
\text { In HBSS† } \\
\text { In 4\% ZTS } \\
\text { In FMLP }\left(10^{-8} \mathrm{M}\right) \\
\text { Toward ZTS } \\
\text { Toward FMLP }\left(5 \times 10^{-7} \mathrm{M}\right)\end{array}$ & $\begin{array}{l}0.68(0.31)^{*} \\
1.61(0.52) \\
2.62(0.58) \\
1.47(0.76) \\
3.13(0.73)\end{array}$ & $\begin{array}{l}0.84(0.33) \\
1.67(0.62) \\
2.41(0.65) \\
1.63(0.59) \\
3.02(0.65)\end{array}$ & $\begin{array}{l}0.74(0.28) \\
1.52(0.67)^{* *} \\
2.23(0.60) \\
1.41(0.56) \\
2.79(0.70)\end{array}$ & $\begin{array}{l}0.78(0.28) \\
1.88(0.82) \\
2.12(0.69) \\
1.58(0.68) \\
2.75(0.72)\end{array}$ \\
\hline $\begin{array}{l}\text { Migration into membrane filter }(\mu \mathrm{m}) \text { : } \\
\text { In HSA } \\
\text { In } 12 \% \text { ZTS } \\
\text { Toward } 12 \% \text { ZTS }\end{array}$ & $\begin{array}{l}40(11) \\
74(17) \\
71(23)\end{array}$ & $\begin{array}{l}39(13) \\
69(19) \\
69(27)\end{array}$ & $\begin{array}{l}42(9) \\
76(24)^{*} \\
72(27)\end{array}$ & $\begin{array}{l}43(12) \\
71(20) \\
65(23)\end{array}$ \\
\hline $\begin{array}{l}\text { Chemiluminescence response, peak (mV) } \\
\text { PBS } \neq \\
\text { FMLP } \\
\text { PMA } \\
\text { Zymosan }\end{array}$ & $\begin{array}{l}0 \cdot 5(0 \cdot 4) \\
4 \cdot 8(2 \cdot 9) \\
6 \cdot 3(7 \cdot 0) \\
11 \cdot 7(10 \cdot 4)\end{array}$ & $\begin{array}{r}0 \cdot 6(0 \cdot 7) \\
5 \cdot 9(3 \cdot 8) \\
6 \cdot 8(7 \cdot 3) \\
11 \cdot 8(7 \cdot 8)\end{array}$ & $\begin{array}{c}0 \cdot 6(0 \cdot 7) \\
5 \cdot 8(4 \cdot 1) \\
6 \cdot 9(4 \cdot 4) \\
15 \cdot 8(15 \cdot 3)\end{array}$ & $\begin{array}{l}0 \cdot 6(0 \cdot 7) \\
7 \cdot 1(7 \cdot 6) \\
6 \cdot 1(4 \cdot 3) \\
13 \cdot 8(10 \cdot 7)\end{array}$ \\
\hline
\end{tabular}

${ }^{*} \mathrm{p}<0.05 ;{ }^{* *} \mathrm{p}<0.02$; paired sample $t$ test between patients and controls.

tHBSS = Hanks's balanced salt solution; ZTS =zymosan treated pooled normal human serum; FMLP $=N$-formyl-methionyl-leucylphenylalanine; HSA=human serum albumin; PBS=phosphate buffered saline; PMA=phorbol myristate acetate. phenylalanine;
$\ddagger$ PSA

$t$ test. Comparisons between polymorphonuclear leucocyte functions of patients with severe or mild acute disease were made with Student's $t$ test.

\section{Results}

CHEMOTAXIS

At the acute phase of the disease the synovial fluid PMN, tested by the agarose assay, showed significantly decreased migration in response to ZTS and FMLP (chemotaxis) and also in ZTS and in FMLP (chemokinesis), whereas spontaneous migration towards HBSS was not affected (fig 1). Also, in the filter assay, synovial fluid PMN tended to show depressed chemotaxis and chemokinesis, though the difference was statistically significant only in the study of migration towards ZTS (fig 2). The rates of migration of the peripheral blood PMN were very similar to those of the control PMN in both assays (figs 1 and 2). The patients' peripheral PMN had, however, a decreased chemokinetic migration under agarose in ZTS.

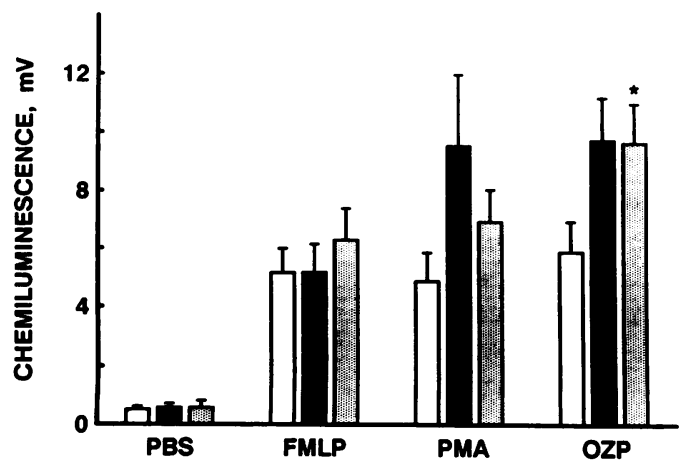

Figure 3: Peak chemiluminescence responses of synovial fluid polymorphomuclear leucocytes (PMN) (open columns) and peripheral blood PMN of the patients (black columns) and the controls (hatched columns) at the acute phase of the disease. $P B S=$ phosphate buffered saline; $F M L P=N$ formyl-methionyl-leucyl-phenylalanine; PMA =phorbol myristate acetate; $O Z P=$ opsonised zymosan particles. Each bar indicates ISE. The significance of the difference between synovial cells and peripheral blood cells is indicated by asterisk: ${ }^{*} p<0.05$.
At one month both the chemotactic and chemokinetic migration rates of the patients' PMN and the control PMN were much the same, whereas the spontaneous migration of the patients' PMN under agarose, but not in the filter, was decreased (table 2).

At six months after recovery, the chemokinetic and chemotactic responses of the patients' PMN to ZTS were in the agarose assay significantly lower and in the membrane filter technique significantly higher than those of the control PMN (table 2).

\section{CHEMILUMINESCENCE}

At the acute phase the peak chemiluminescence response of the synovial PMN to opsonised zymosan particles was significantly lower than that of control PMN (fig 3). The response to phorbol myristate acetate, but not to FMLP, also tended to be decreased, though not significantly (fig 3). The responses of the patients' peripheral blood PMN and control PMN were much the same at the acute phase, at one month, and at six months (fig 3 and table 2). The shapes of the chemiluminescence curves of the three groups were similar and analysis of the areas under the curves showed findings identical to the peak responses (data not shown).

\section{EFFECT OF THE SEVERITY OF THE DISEASE}

At the acute phase the chemiluminescence response induced by phorbol myristate acetate of the synovial fluid PMN of the patients with severe disease, mean (SD), was significantly higher than that of patients with mild disease: $76(3.3) \mathrm{mV} v 3.8(2.6) \mathrm{mV}, \mathrm{p}<0.05$. At six months the peripheral blood PMN of the group with severe disease showed significantly higher rates of migration, mean (SD), than those of the group with mild disease: under agarose in ZTS $1.98(0.49) \mathrm{mm} v 1.06(0.51) \mathrm{mm}, \mathrm{p}<0.02$; in the filter in the presence of HSA 48 (9) $\mu \mathrm{m} v 35$ (5) $\mu \mathrm{m}, \mathrm{p}<0.02$; and in the filter toward ZTS 88 (26) $v 56(18) \mu \mathrm{m}, \mathrm{p}<0.05$. 
Discussion

These findings indicate that chemotactic and chemokinetic migration of synovial fluid PMN of patients with acute reactive arthritis is depressed, and oxygen radical production determined by the luminol enhanced chemiluminescence assay is also depressed or similar to that of peripheral blood PMN of the patients and healthy control subjects. These functional aberrations suggest that the patients' synovial fluid PMN are deactivated. ${ }^{6}$

Deactivation of synovial fluid PMN occurs in patients with rheumatoid arthritis, ${ }^{13}{ }^{14}$ possibly owing to the ingestion of immune complexes by PMN. Under experimental conditions PMN exposed to small size aggregated IgG show decreased stimulated migration ${ }^{20}$ and decreased chemiluminescence responses, ${ }^{21} 22$ whereas large aggregates are stimulatory. ${ }^{20}$ Some patients with yersinia arthritis have circulating yersinia specific immune complexes of small size $\mathrm{e}^{23}$ and also yersinia specific immune complexes in synovial fluid. ${ }^{24}$ The presence of microbial structures in the joint fluid is further supported by the finding of chlamydia and yersinia antigens in the synovial fluid cells of patients with reactive arthritis triggered by chlamydia urethritis ${ }^{25}$ and yersinia enteritis. ${ }^{26}$ Thus deactivation is a characteristic of synovial fluid PMN in both rheumatoid arthritis ${ }^{1314}$ and seronegative reactive arthritis as shown in this study and, possibly, immune complexes contribute to both disorders.

The mechanism of deactivation is not known but it may entail auto-oxidation of PMN; this is supported by the findings that oxygen radical scavengers potentiate chemotaxis ${ }^{27}$ and that PMN of patients with chronic granulomatous disease, which cannot generate oxygen radicals, do not become deactivated. ${ }^{28}$ It is also possible that the non-steroidal anti-inflammatory drugs taken by our patients may inhibit chemotaxis ${ }^{29}$ and production of oxygen derived free radicals. ${ }^{12}$ 30-32 This explanation is not supported by the finding that the patients' peripheral blood PMN were functionally normal and not deactivated.

In this study chemotactic/chemokinetic migration of the patients' purified peripheral blood PMN was similar to that of control PMN during the acute disease, whereas after recovery the chemokinetic responses oई the patients' PMN to ZTS were depressed in the agarose assay and increased in the filter assay. These findings differ from those in our previous study, ${ }^{3}$ which showed that both at the acute phase and after recovery buffy coat PMN of HLA-B27 positive patients with yersinia arthritis showed increased migration in response to ZTS. Buffy coat does also contain monocytes which increase migration of PMN in vitro. ${ }^{33}$ Monocytes of the patients with previous yersinia arthritis generate increased amounts of tumour necrosis factor. ${ }^{34}$ Tumour necrosis factor may contribute to increased chemotaxis/chemokinesis of the patients' buffy coat PMN by inducing generation of monocyte derived chemotactic factors for PMN. ${ }^{35}$ Furthermore, recombinant tumour necrosis factor has been reported by some ${ }^{36}$ but not all ${ }^{37}$ authors to be chemotactic for PMN.
After recovery the peripheral blood PMN of patients with severe acute disease showed higher chemotactic migration than did those with mild disease, which agrees with our previous study. We have also previously shown that PMN of the patients who have sequelae tend to show increased migration. ${ }^{5}$ These findings support the view that among patients with reactive arthritis there are subgroups with hyperreactive neutrophils, which may contribute to the development of severe inflammatory symptoms. Clinical studies also provide evidence of subgroups: according to the 10 year follow up study about $30 \%$ of patients with yersinia arthritis develop sacroiliitis, even ankylosing spondylitis. ${ }^{38}$ It is interesting that purified PMN of patients with ankylosing spondylitis show increased chemotactic responses to $\mathrm{ZTS}^{39}{ }^{40}$ but not to FMLP, ${ }^{41}$ both under agarose and in the filter. Thus the data suggest that increased migration of PMN in response to ZTS is most pronounced, and can be shown also using purified PMN, in patients with severe inflammatory tissue injury, which occurs in ankylosing spondylitis and possibly in reactive arthritis characterised by severe acute disease or late complications. On the other hand, in patients with mild, self limited reactive arthritis, enhanced migration of PMN would be more evident in the presence of both PMN and monocytes. Because microbial antigens may occur $^{242542}$ and persist ${ }^{2643}$ in the host tissues, an interesting possibility is that such bacterial structures modify monocyte/macrophage function and thereby also functions of PMN in patients with reactive arthritis.

The skilful technical assistance of Mrs Eine Virolainen and Mrs Paula Rahikainen is gratefully acknowledged. The study was supported by grants from the Paulo Foundation, the Academy of Finland, the Rheumatism Research Foundation, the Finnis Medical Foundation, and the Finnish Cultural Foundation.

1 Aho K, Leirisalo-Repo M, Repo H. Reactive arthritis. Clin Rheum Dis 1985; 11: 25-40.

2 Lauhio A, Lähdevirta J, Janes R, Kontiainen S, Repo H. Reactive arthritis associated with Shigella sonnei infection. Arthritis Rheum 1988; 31: 1190-3.

3 Leirisalo M, Repo H, Tiilikainen A, Kosunen T U, Laitinen $O$. Chemotaxis in yersinia arthritis: HLA-B27 positive neutrophils show high stimulated motility in vitro. Arthritis Rheum 1980; 23: 1036-44.

4 Koivuranta-Vaara P, Leirisalo-Repo M, Repo H. Poly morphonuclear leucocyte function and previous yersinia arthritis: enhanced chemokinetic migration and oxygen radical production correlate with the severity of the acute disease. Ann Rheum Dis 1987; 46: 307-13.

5 Repo H, Koivuranta-Vaara P, Leirisalo-Repo M. Polymorphonuclear leucocyte function and previous yersinia arthritis: correlation of enhanced superoxide production with late manifestations. Ann Rheum Dis 1988; 47: 452-7.

6 Zimmerli W, Seligmann B, Gallin J I. Exudation primes human and guinea pig neutrophils for subsequent responsiveness to the chemotactic peptide $\mathrm{N}$-formylmethionylleucylphenylalanine and increases complement componen leucylphenylalanine and increases complement componen

7 Bender J G, McPhail L C, van Epps D E. Exposure of human neutrophils to chemotactic deactivation of human neutrophil: possible relationship to stimulation of oxidative metabolism. F Immunol 1983; 130: 3216-23.

8 Turner $R$ A, Johnson J A, Turner $S R$. Neutrophil responsiveness to chemoattractant tripeptide in rheumatoid arthritis. Proc Soc Exp Biol Med 1987; 186: 125-33.

9 Goddard D H, Kirk A P, Kirwan J R, Johnson G D Holborow E' J. Impaired polymorphonuclear leucocyte chemotaxis in rheumatoid arthritis. Ann Rheum Dis 1984 43: 151-6.

10 Hanlon S M, Panayi G S, Laurent R. Defective polymorphonuclear leucocyte chemotaxis in rheumatoid arthritis associated with a serum inhibitor. Ann Rheum Dis 1980; 39 : 68-74.

11 Howe G B, Fordham J N, Brown K A, Currey H L F Polymorphon's syndrome. Ann Rheum Dis 1981; 40: 370-5. 
12 Biemond P, Swaak A J G, Penders J M A, Beindorf C M, Koster J F. Superoxide production by polymorphonuclear leucocytes in rheumatoid arthritis and osteoarthritis: in vivo inhibition by the antirheumatic drug piroxicam due to interference with the activation of the NADPH-oxidase. Ann Rheum Dis 1986; 45: 249-55.

13 Kemp A S, Brown S, Brooks P M, Neoh S H. Migration of blood and synovial fluid neutrophils obtained from patients blood and synovial fluid neutrophils obtained from patients with 6 .

14 James D W, Betts W H, Cleland L G. Chemiluminescence of polymorphonuclear leukocytes from rheumatoid joints. f Rheumatol 1983; 10: 184-9.

15 Böyum A. Separation of blood leukocytes, granulocytes and lymphocytes. Tissue Antigens 1974; 4: 269-74.

16 Repo H, Kosunen T U. Leukocyte migration agarose test for the assessment of human neutrophil chemotaxis. II. Variables in the attraction assay. Scand F Immunol 1977; 6: 211-8.

17 Zigmond S H, Hirsch J G. Leukocyte locomotion and chemotaxis. New methods for evaluation, and demonstration of a cell-derived chemotactic factor. $\mathcal{F}$ Exp Med 1973 ; tion of a cell-der

18 Boyden S. The chemotactic effect of mixtures of antibody and antigen on polymorphonuclear leukocytes. $\mathcal{f}$ Exp Med 1962; 115: 453-66.

19 Wilkinson P C. Chemotaxis and inflammation. Edinburgh: Churchill Livingstone, 1974: 168-72.

20 Goddard D H, Kirk A P, Brown K A, McCarthy D, Johnson G D, Holborow E J. Changes in normal polymorphonuclear leucocyte motility after ingestion of IgG aggregates. Am Rheum Dis 1984; 43: 146-50.

21 Starkebaum G, Stevens D L, Henry C, Gavin S E. Stimulation of human neutrophil chemiluminescence by soluble immune complexes and antibodies to neutrophils. soluble immune complexes and an

22 Gale R, Bertouch J V, Gordon T P, Bradley J, RobertsThomson P J. Neutrophil activation by immune complexes and the role of rheumatoid factor. Ann Rheum Dis 1984; 43: 34-9.

23 Lahesmaa-Rantala R, Granfors K, Lehtonen O-P, Toivanen A. Characterization of circulating yersinia-specific immune complexes in patients with yersiniosis. Clin Immunol Immunopathol 1987; 42: 202-10.

24 Lahesmaa-Rantala R, Granfors K, Isomäki H, Toivanen A. Yersinia specific immune complexes in the synovial fluid of patients with patients with yersinia trig
Rheum Dis 1987; 46: $510-4$.

25 Keat A, Thomas B, Dixey J, Osborn M, Sonnex C, TaylorRobinson D. Chlamydia trachomatis and reactive arthritis: the missing link. Lancet 1987; i: 72-4.

26 Granfors K, Jalkanen S, von Essen R, et al. Yersinia antigens in synovial-fluid cells from patients with reactive arthritis. $N$ Engl f Med 1989; 320: 216-21.

27 Baehner R L, Boxer L A, Allen J M, Davis J. Autooxidation as a basis for altered function by polymorphonuclear leukocytes. Blood 1977; 50: 327-35.

28 Nelson R D, McCormack R T, Fiegel V D, Herron $M$ Simmons P $L$, Quie P G. Chemotactic deactivation of human neutrophil. possible relationship to stimulation o oxidative metabolism. Infect Immun 1977; 23: 282-6.
29 Forsgren A, Sheja A. Experience with skin chamber technique for leucocyte migration studies. Immunol Lett 1985; 11 : 253-9.

30 Miller C, Russell A S. The generation of superoxide anions by polymorphonuclear leucocytes from patients with ankylosing spondylitis in response to the stimulant f-met-leu-phe. ing spondylitis in response to the stim

31 Müller-Peddinghaus $R$, Wurl $M$. The amplified chemiluminescence test to characterize antirheumatic drugs as oxygen radical scavengers. Biochem Pharmacol 1987; 36: $1125-32$.

32 Neal T M, Vissers M C M, Winterbourn C C. Inhibition by nonsteroidal anti-inflammatory drugs of superoxide production and granule enzyme release by polymorphonuclear leukocytes stimulated with immune complexes or formylmethionyl-leucyl-phenylalanine. Biochem Pharmacol 1987; 36: $2511-7$.

33 Repo H, Savilahti E, Leirisalo-Repo M. Aberrant phagocyte function in Shwachman syndrome. Clin Exp Immunol 1987; 69: 204-12.

34 Repo H, Jäättelä M, Leirisalo-Repo M, Hurme M. Production of tumor necrosis factor and interleukin 1 by monocytes of patients with previous yersinia arthritis. Clin Exp Immunol 1988; 72: 410-4.

35 Matsushima K, Morishita K, Yoshimura T, et al. Molecula cloning of a human monocyte-derived neutrophil chemotactic factor (MDNCF) and the induction of MDNCF tactic factor (MDNCF) and the induction of MDNCF Med 1988; 167: 1883-93.

36 Newman I, Wilkinson P C. Chemotactic activity of lymphotoxin and tumour necrosis factor alpha for human neutrophils. Immunology 1989; 66: 318-20.

37 Kownatzki E, Kapp A, Uhrich S. Modulation of human neutrophilic granulocyte functions by recombinant human tumor necrosis factor and recombinant human lymphotoxin. Promotion of adherence, inhibition of chemotactic migration and superoxide anion release from adherent cells. Clin Exp Immunol 1988; 74: 143-8.

38 Leirisalo-Repo M, Suoranta $\mathrm{H}$. Ten-year followup study of patients with yersinia arthritis. Arthritis Rheum 1988; 31 : patien

39 Pease C T, Fordham J N, Currey H L F. Polymorphonuclear cell motility, ankylosing spondylitis, and HLA-B27. Ann Rheum Dis 1984; 43: 279-84.

40 Pease C T, Fennell M, Brewerton D A. Polymorphonuclear leucocyte motility in men with ankylosing spondylitis. Ann Rheum Dis 1989; 48: 35-41.

41 El Abbouyi A, Paul L J, Roch-Arveiller M, et al. Blood polymorphonuclear behavior in patients with ankylosing spondylitis. Clin Exp Rheumatol 1988; 6: 401-3.

42 Schumacher H R Jr, Magge S, Cherian P V, et al. Light and electron microscopic studies on the synovial membrane in Reiter's disease. Immunocytochemical identification of chlamydial antigen in patients with early disease. Arthriti Rheum 1988; 31: 937-46.

43 de Koning J, Heesemann J, Hoogkamp-Korstanje J A A, Festen J J M, Houtman P M, van Oijen P L M. Yersinia in intestinal biopsy specimens from patients with seronegative spondyloarthropathy: correlation with specific serum IgA spondyloarthropathy: correlation with spec 